\title{
Framework to Assist Professionals from Architecture, Engineering and Construction (Aec) Implementing Building Information and Modelling (Bim) with Respect to Structural Discipline
}

\author{
* Aniruddh A. Bilodi, Mohd Rashid, Kousay Al Sanjery, Salmaliza Salleh \\ Centre of Geo-Hazards in Structures Related to Structural and Foundation \\ Design, Reliability Management \& Materials,
}

Faculty of Engineering and the Built Environment, SEGi University

*aniruddh_ab@yahoo.com

\begin{abstract}
Building Information and Modelling (BIM) is a technology that allows Architecture, Engineering and Construction (AEC) professionals to digitally design, test, construct and manage the infrastructure. BIM in construction projects has not been fully implemented, due to lack of effective strategy in the implementation of BIM. AEC industries struggles to implement BIM because of the absence of a Real-World BIM sample and BIM framework. This research aims to navigate AEC professionals to implement BIM with respect to structural discipline and this paper will also help to understand the coordination between other disciplines where one discipline model is superimposed on another discipline model. This paper will also help to understand different global BIM standards and the most efficient and effective BIM tools used all over the world. AEC professionals need assistance in the form of a framework which would provide a road map to process and implement BIM. Thus, the framework provided in the paper expected to increase BIM implementation and eventually widen the usage of BIM.
\end{abstract}

Keywords: Structural discipline, Superimposition, BIM standards, BIM tools, BIM Framework, BIM implementation 


\section{Introduction}

Building Information Modelling (BIM) is a detailed simulation of each element of the construction process and beyond in a virtual environment. It is the smartest and the most promising development happening in Architecture, Engineering and Construction industry. It allows AEC professionals to access the whole construction process and beyond construction in a virtual environment through a prototype. The prototype contains accurate geometry and precise data, which helps AEC professionals to understand the construction process in virtual reality. Basically, BIM is a data-rich, objectoriented, intelligent and parametric digital representation of the structure, from which concerned activist can extract specific data and analyze it. Later the data can be used to make decisions and implement them on the field. BIM is also unequivocally tool of collaboration. Collaboration in the design and construction decreases design mistakes and increases the productivity of the construction industry (Javad Majrouhi Sardroud, 2018). BIM is a structured approach where most of the developed countries have been utilizing it and such country's respective government is also ensuring that the private sector is adopting the usage of BIM in their practice. BIM dimensions are beyond 3 dimensions. BIM integration of dimension could be built up till 7 dimensions that encompass building geometry (3D), quantity surveying and costing (4D), schedule of construction (5D), sustainability (6D) and facility management (7D). BIM incorporates all the section of construction from design, analysis, construction, operation, legal documents, and data management. BIM technology also serves as a platform where AEC professional efficiently and effectively communicate during the whole process of the construction (Pranav Bhagwat, 2016).

\section{Problem Statement}

The absence of a Real-World BIM-based framework and BIM sample in the current AEC industry is one of the major problems which have come across in Small and Medium Enterprise (SME's) in developing countries. This research aims to navigate construction players with respect to structural 
discipline to implement BIM and this paper will also help to understand the coordination between other discipline while implementing BIM.

\section{Literature Review}

Adaptation of technology in the AEC industry is moving rapidly towards the era of globalization and modernization. Information, Communication, and Technology have played a vital role in this transition era (Zahrizan, 2014). Where the early concept of BIM dates back to the 1970s and 1980s when the computer-aided design (CAD) was introduced and the creation of the ArchiCAD software in Hungary in 1982 was the real beginning of BIM, and Revit software in 2000 is considered a major turning point in the implementation of BIM (Javad Majrouhi Sardroud, 2018). There are several hurdles to implement BIM in construction sector like the cultural issue, an economic issue, legal and policy issue, the absence of real-time sample is also one of the major issues. This paper will be focusing on the absence of realtime sample to set a framework for processing BIM in the construction sector. Approach to persuading stakeholders to use BIM technology is the availability of run-time examples of projects implemented using BIM technology (Javad Majrouhi Sardroud, 2018).

British Standards Institution (BSI) has set a standard globally for the construction sector to implement BIM. BSI basic standard for BIM implementation is called BIM level 2. As shown in the Figure 1, according to Bew-Richards maturity model there are several maturity levels at which BIM is implemented. The BIM level 0 is an unmanaged computer-aided drawing, BIM level 1 or Phase 1 is a 3D model and BIM level 2 or Phase 2 is a collaborative detailed 3D model in an environment where each discipline model is built separately and collaborated at one platform. 


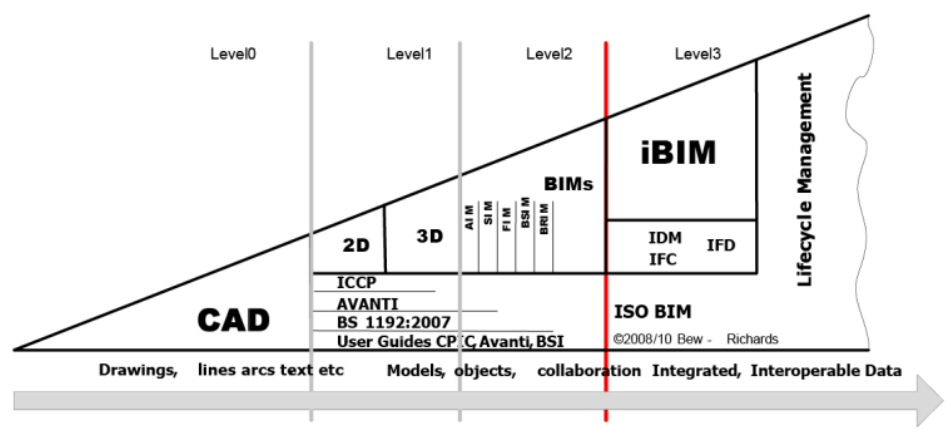

Figure 1. Bew-Richards maturity model (Weddikkara, 2013)

In May 2011, the United Kingdom government published the Construction Strategy aimed at reducing the cost of public sector assets by up to $20 \%$ by 2016 ((BSI), 2016). Such a strategy has been achieved in developed countries, where the authority of the AEC industry in both the private sector and public sector has made it mandatory by including it in their tender requirements. BIM Level 2 adoption by the AEC industry requires individuals and organizations to embrace the change and accept the modern roles of operation between the activists which has been redefined in every sector. The International Organization for Standardization (ISO) has released the world's first international standards for BIM, the ISO 19650-1 and ISO 19650-2 ((ISO), 2018).

In Malaysia, BIM started in the year 2009 by the private sector. Later, the Malaysian government announced its first project National Cancer Institute (NCI) under BIM in the year 2010. Authority like Construction Industry Development Board (CIDB) has already started to understand the importance of BIM in the AEC industry, CIDB complements the AEC industry by giving a platform where the usage of BIM could survive and thrive. CIMB has been putting effort to implement BIM by providing awareness programs, workshops, and engaging industry activists at one platform. CIDB is also in the midst of establishing the National BIM Committee of Building Information Modelling in the construction Industry in order to coordinate the movement of BIM in the country ((CREAM), 2014). 
CIDB has recommended making BIM mandatory in certain private sector projects by 2020 .

\section{Tool Usage}

According to the National Building Specification (NBS) Report 60 percent of BIM user uses Autodesk (NBS, 2018) around the world. In that 44 percent of 60 percentage uses Autodesk Revit and the remaining 16 percent use other Autodesk tools. Software used as BIM tool under Autodesk are Revit, AutoCAD, Navisworks, Infraworks, Civil 3D, 3ds Max, and BIM 360.

Revit - It is a software which is been used since the year 2000 and is considered as a major turning point in the AEC industry to implement BIM. Autodesk Revit is a BIM tool that helps designers, contractors, architects, structural engineers, and MEP engineers by providing incredible data-rich, intelligent, parametric digital, and object-oriented representation of the building or the structure from which concerned user can extract specific data and then analyze it, which can be used to make decisions and later implement them on the field.

AutoCAD - It is a computer-aided drafting tool in 2 dimensions and 3 dimensions which is used in the AEC industry and even in the manufacturing industry which helps to prepares blueprints and plans.

Navisworks - It is a powerful 3D review tool primarily used in the AEC industry. It complements 3D models of AutoCAD, Autodesk Revit, and MicroStation. Navisworks tool runs only on the Windows operating system platform. Major features of Navisworks are interference detection (Clash detection), 4D time simulation, Quantification, photorealistic rendering, and PDF-like publishing.

Infraworks - It is a planning, designing, and simulation tool of infrastructure which provides a platform for engineers to interact with the realworld virtual site. Engineers can easily convey their design to stakeholders and other concerned AEC activists using this tool. 
3ds Max - It is a graphical programming 3D animation software where it is usually used for animations, models, games and at high quality rendering purpose. It is also used in architectural visualization studios and even as BIM tool.

BIM 360 - It is a collaborative BIM cloud where construction players are associated with the project. Construction players can also communicate and manage their respective work remotely but from one single platform. 360 provides a central workspace in the cloud for the people working on the project. Construction players can view 2D and 3D design of the project using the BIM 360 viewer on any device.

\section{BIM Framework}

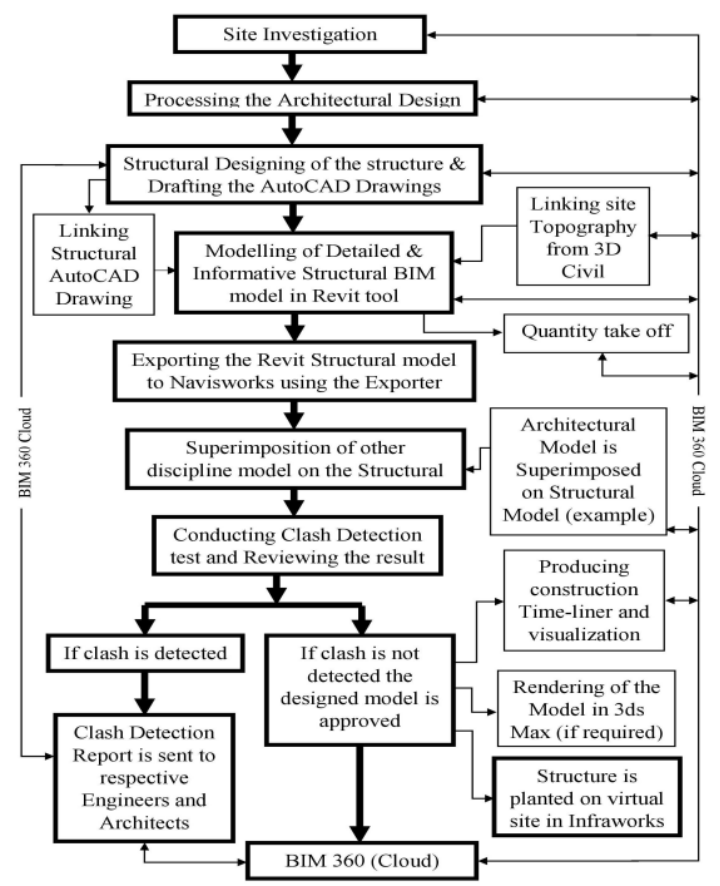

Figure 2. Framework to implement BIM with respect to Structural discipline

\subsection{Implementation of BIM Using the Framework}

BIM is a process of construction which is primarily driven digitally, informatively, and systematically. To implement such a process sophisticated 
software or tools are required. For this paper, Autodesk tools are considered because $60 \%$ of the world uses Autodesk for BIM this is according to National Bureau of Standards (NBS). The composite structure is considered as a sample for this paper where information of the project is collected through several site visit, from engineers, architects, contractors and clients and all the information acquired is used for building the framework to implement BIM.

Interoperability - Before starting BIM implementation process Interoperability must be understood. Interoperability is a process of transferring the BIM model from one tool to another tool. It is the ability to communicate between varying types of BIM tools. The idea is to reduce the data loss while transferring the model from one tool to another. BIM engineer must keep interoperability in their mind while transferring data. If any data is lost while transferring the model, BIM engineer must take note of the lost data and remodel it in the new tool.

Revit Template and Family - The first step of using the BIM Revit tool is to select the accurate and discipline-oriented template. This will help the BIM engineer to process and use the Revit tool to its complete extent. If an appropriate template is not chosen correctly modeling of the structure will be completed, then BIM engineer must remodel the work from the start using the appropriate template. There are several types of Revit template which are architectural template, structural template, mechanical template, electrical template, and plumbing template. Templates could be customized depending upon the project usage and BIM engineer's and project's requirement.

AutoCAD process - After the site inspection architect designs the structure according to the client's requirements. Once the architectural design is confirmed and granted, the architectural drawings are extracted. Architectural drawings are extracted in AutoCAD in DWG format. Then the architectural drawing goes to the engineer for structural designing purpose. Structural engineer goes through the architectural drawing and designs the structure under the respective conditions. After the completion of the structural designing, structural drawings are extracted in AutoCAD in DWG 
format. Once drawings are extracted in AutoCAD, coordinate each model with respect to other discipline.

Revit Process - Revit template is selected with respect to the discipline. Each discipline has its own different model, hence each model is built in its own respective discipline template. Revit models are primarily divided into 3 categories,

- $\quad$ Architectural model

- $\quad$ Structural model

- $\quad$ MEP model (Mechanical Electrical and Plumbing)

This paper majorly concentrates on the implementation of BIM with respect to structural discipline. Clients requirement with respect to Level of Detail (LOD) or Level of Information (LOI) should be consulted and taken into consideration. Structural Template is selected before modeling the structural model. AutoCAD structural drawing of the structure is linked to Revit so that models could be built on similar coordinate. As shown in the figure 3 the model is built with exact precision according to the structural drawings. In reinforced concrete structure each steel bar is calculatedly placed in the model, this will help the contractor to check and to implement the same dimension at the site. The topography of the construction site is extracted by Autodesk Civil 3D in an XML file.

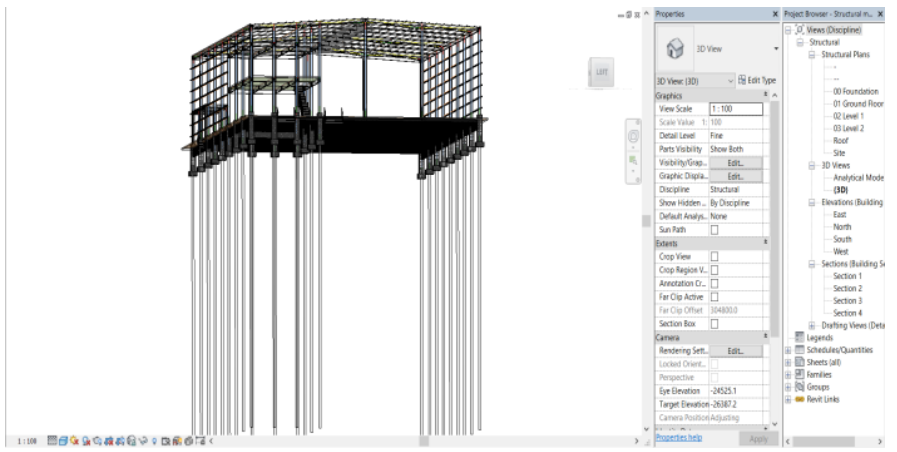

Figure 3. Structural model 
Once the model is built, each element of the model is fed with detailed information according to the clients LOD requirements. Feeding information to each element is one of the major tasks of BIM. This will provide clarity to construction players throughout the life span of the building. As shown in the Figure 3, the stump is modeled exactly and detailed information is being fed to each element using the type properties.

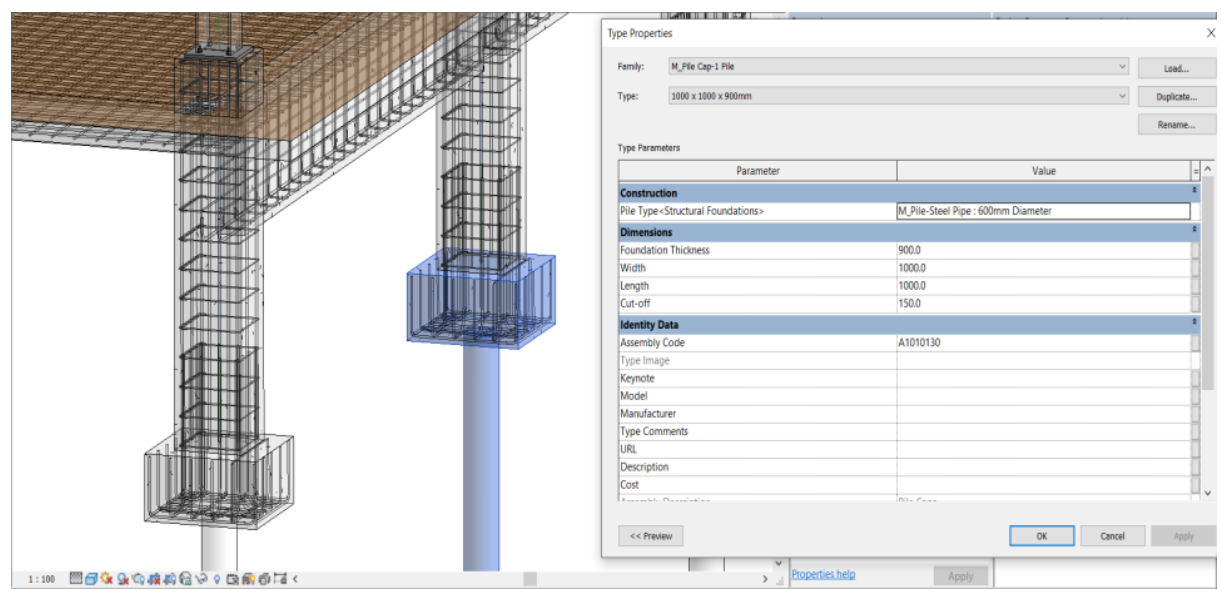

Figure 3. Placement of steel bar in Reinforced Concrete structure and feeding information using properties

Quantity take-off and cost analysis are one of the key features of Revit tool. Once the model is built and all the information is fed then it is easy to extract the cost estimation and quantity from the model, as shown in Figure 4.

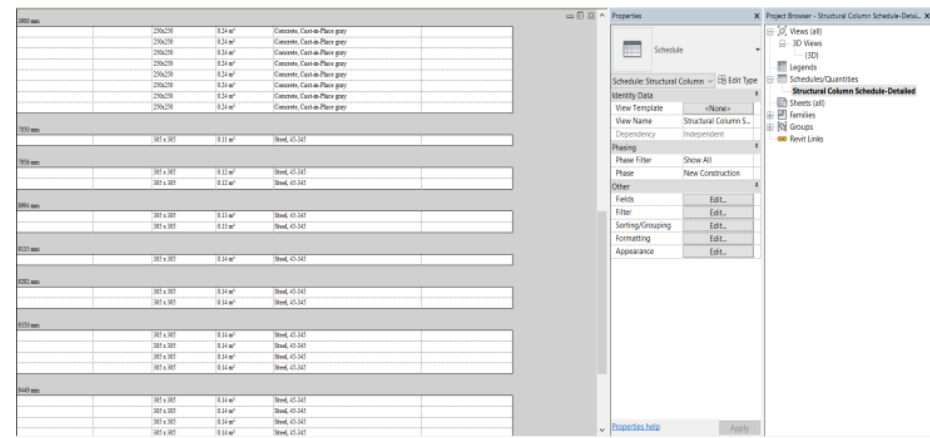

Figure 4. Concrete and steel quantity take off 
Architectural Model - The detailed architectural sample model is built to display the collaboration between Structural Model and Architectural Model. This model will also be used in Navisworks for clash detection purpose. Architectural Template is selected before modeling the architectural model. AutoCAD's architectural drawing of the building is linked to Revit tool so that models could be built on similar standard coordinate.

As shown in Figure 5, the model is built with exact precision according to the architectural drawings. Once model is built, the information is fed to each element of the model. This will provide clarity to construction players throughout the life span of the structure. The topography of the construction site is extracted by Autodesk Civil 3D in an XML file. Once all the above process is over, the engineer's drawing sheets are linked to the model and the informative model is sent to the BIM manager for approval.

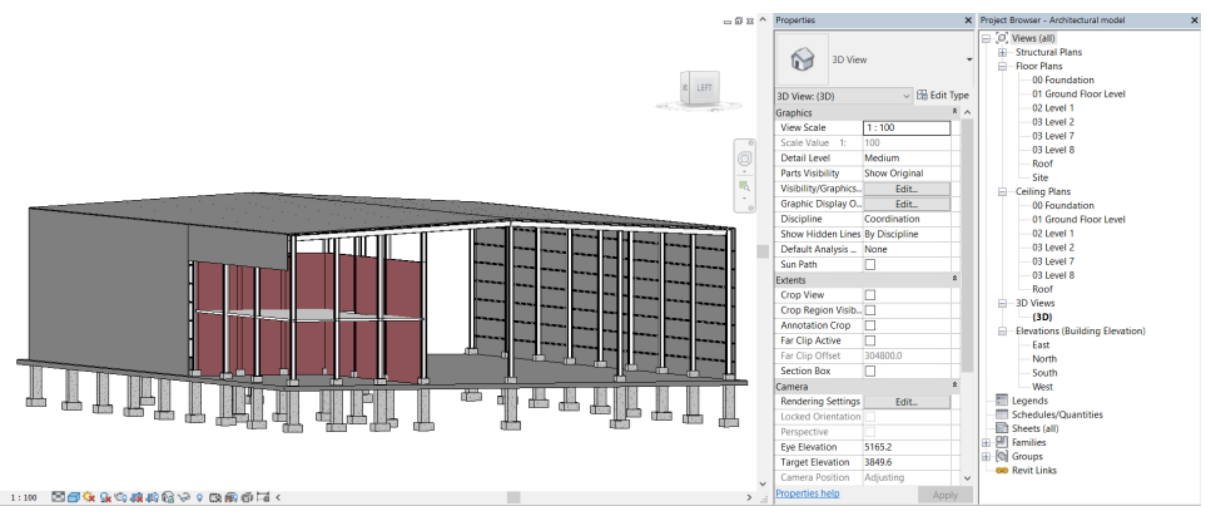

Figure 5. Informative architectural model

Navisworks - Export Informative Architectural model and Informative Structural model into Navisworks, as it shown in Figure 6. Before exporting make sure the coordinates of the respective discipline models are in the same standard coordinate. If not, coordinate the models to one specific location. Navisworks has 2 primary features, Clash detection and Time liner. And other features are quantification, preview, animation and rendering. After clash detection and timeliner process, Navisworks model proceeds for visualization, 
animation and rendering process which helps client and construction players to understand the structure better.

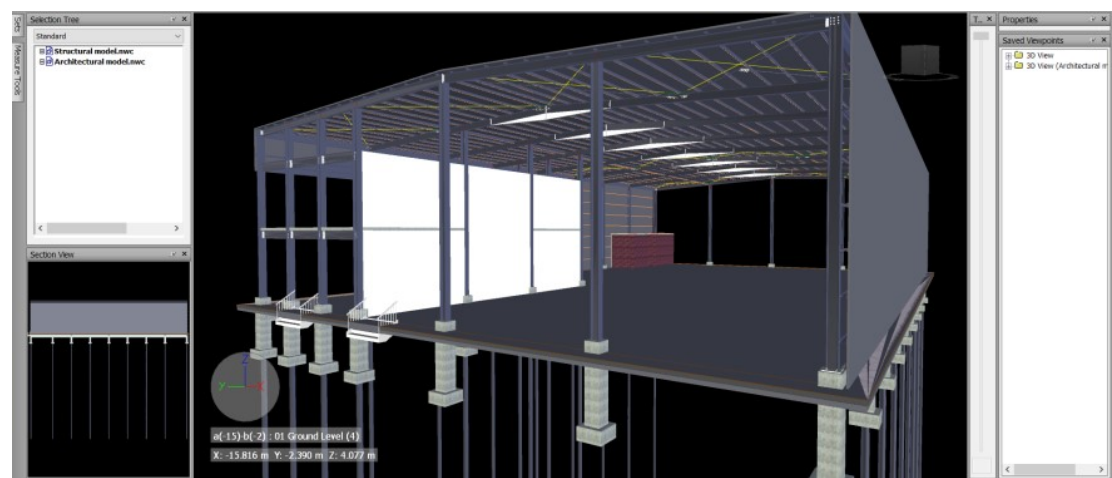

Figure 6. Architectural model superimposed on structural model

Clash detection - Clash detection tool is one of the most powerful tools in BIM. Architectural model and Structural model are superimposed at one common standard coordinate, as shown in Figure 6. When both models are coordinated to one location, clash detection process is carried out between models for any interference. If any interference is found, go back to Revit and amend the structure. Clash detection can easily find flaws in the engineering drawing and construction errors, so it increases the efficiency of the construction process. 121 clashes were detected when the architectural model clashed with the structural model. Different detected clash is as shown in Figure 7, 8, and 9. Clash detection can be classified by Hard clash, duplicate clash, clearance clash, and tolerance level of the clash can also be adjusted depending on the client's requirement. 


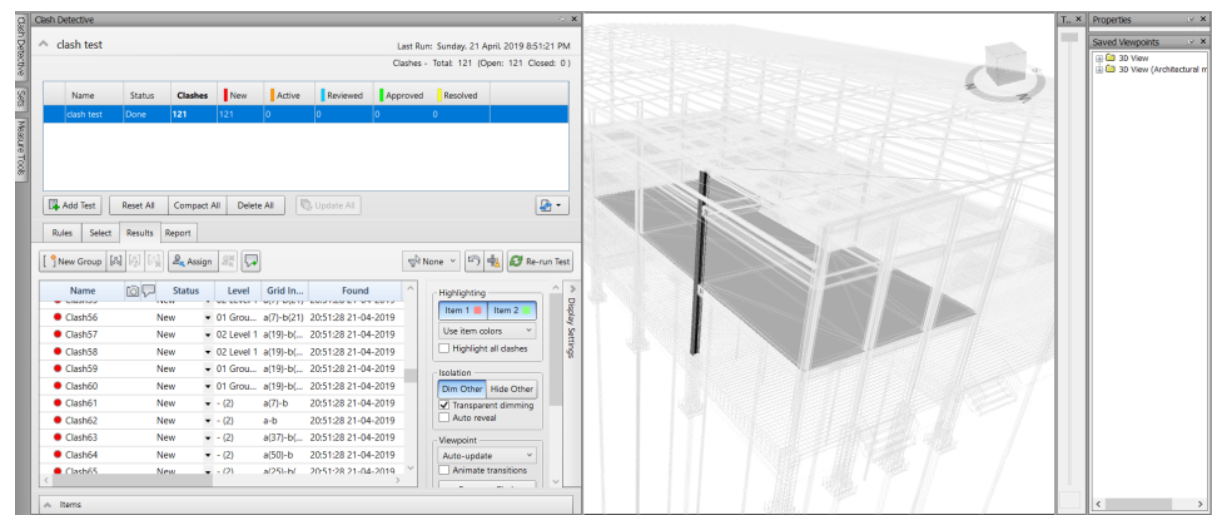

Figure 7. Clash detected between steel column and Office floor

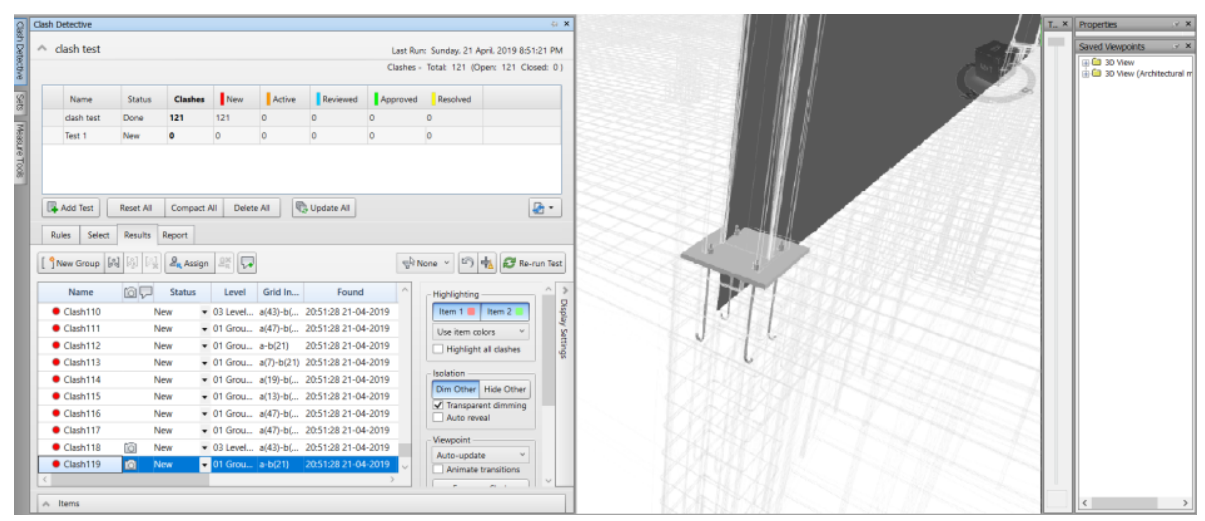

Figure 8. Clash detected between Base plate and wall

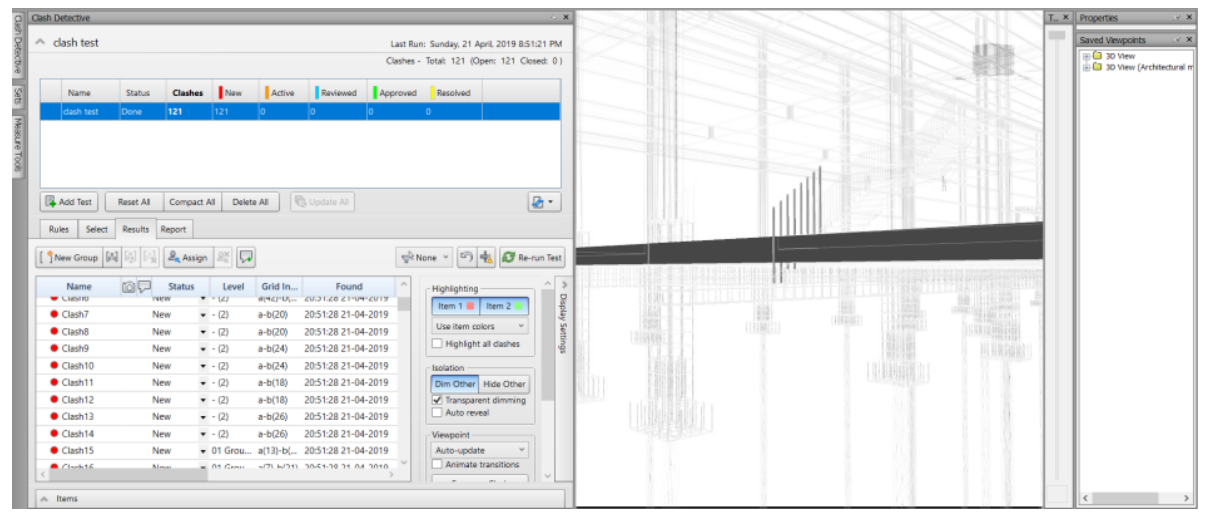

Figure 9. Clash detected between Railing and Raft foundation 
Timeliner - Timeliner tool is a schedule simulation of construction. It helps clients and construction players to view the construction in a virtual simulation. Time liner simulates the construction and duration taken by each part of the construction. Structures progress can be seen in the Figure 10 and Figure 11 during week 27 and week 55 respectively.

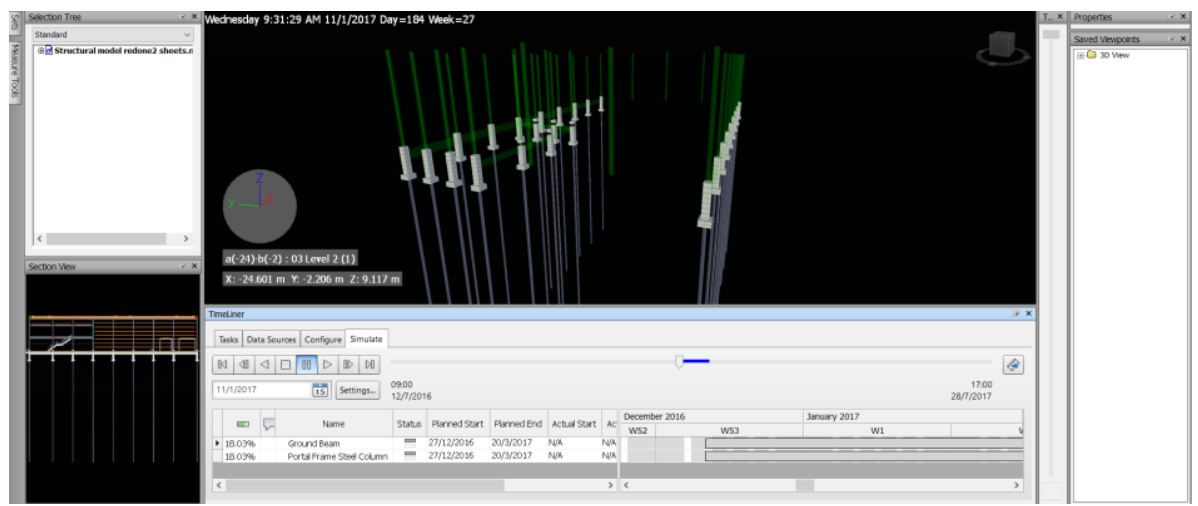

Figure 10. Progress of the construction in 27 weeks

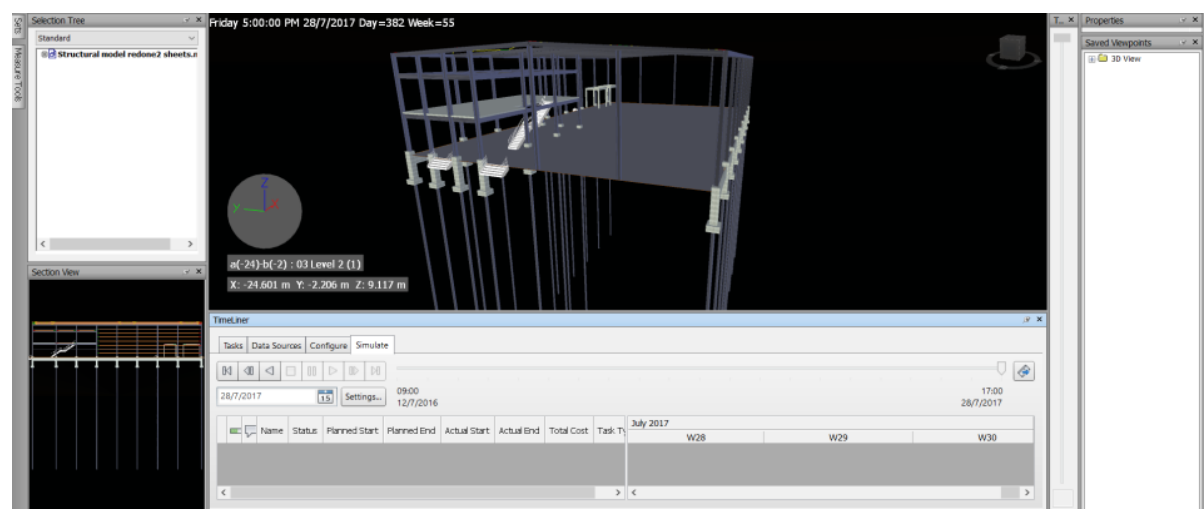

Figure 11. Progress of the construction in 55 weeks

3ds Max - Navisworks model is then imported into 3ds Max for better rendering and animation purpose. Transfer of file is done by exporting the model in FXB format and later importing the same FXB file into 3ds max. Rendered model can been seen in the Figure 12. The quality of visualization in $3 \mathrm{ds}$ Max is better than all the other Autodesk tools. This process is optional in BIM and is only used if the client has mentioned it. 


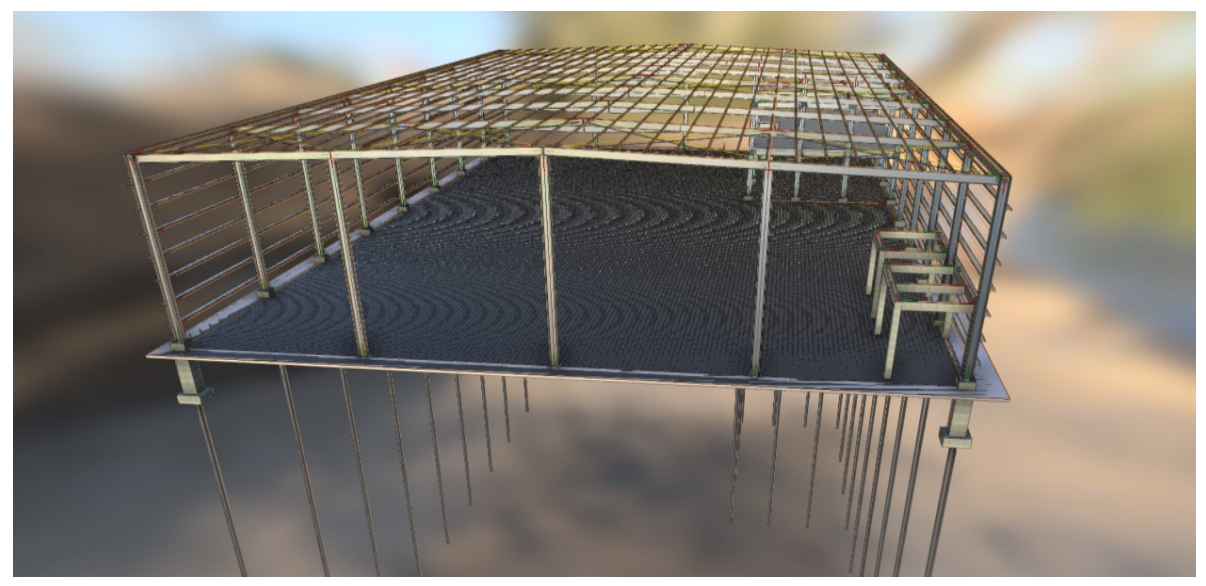

Figure 12. Rendered model

Infraworks - It helps construction players by integrating designed models in a virtual real-world environment. Infraworks extracts the real image of the site from the satellite and creates the exact environment for better conceptual understanding of the building. Initially, site environment is extracted through the satellite from Model Builder. Details of the site must be mention in Model Builder including the size of the area. Process of extraction takes time depending on the size of the site. Once the virtual site is created Revit model is imported into Infraworks. So, after resolving all the clash detection in Navisworks, amended Revit models are imported into Infraworks. Import can be done in two methods which are, by using GIS (Geographic information system) coordinate or by uploading the model into Infraworks, as shown in the Figure 13. After placing the model on the virtual site the artificial sun path, roads, tree, and calculated traffic system can be added to the site. This helps to create a virtual real-world simulation of the Building at the site. Virtual real-world simulation of the Building at the site video can also be created at high resolution. 


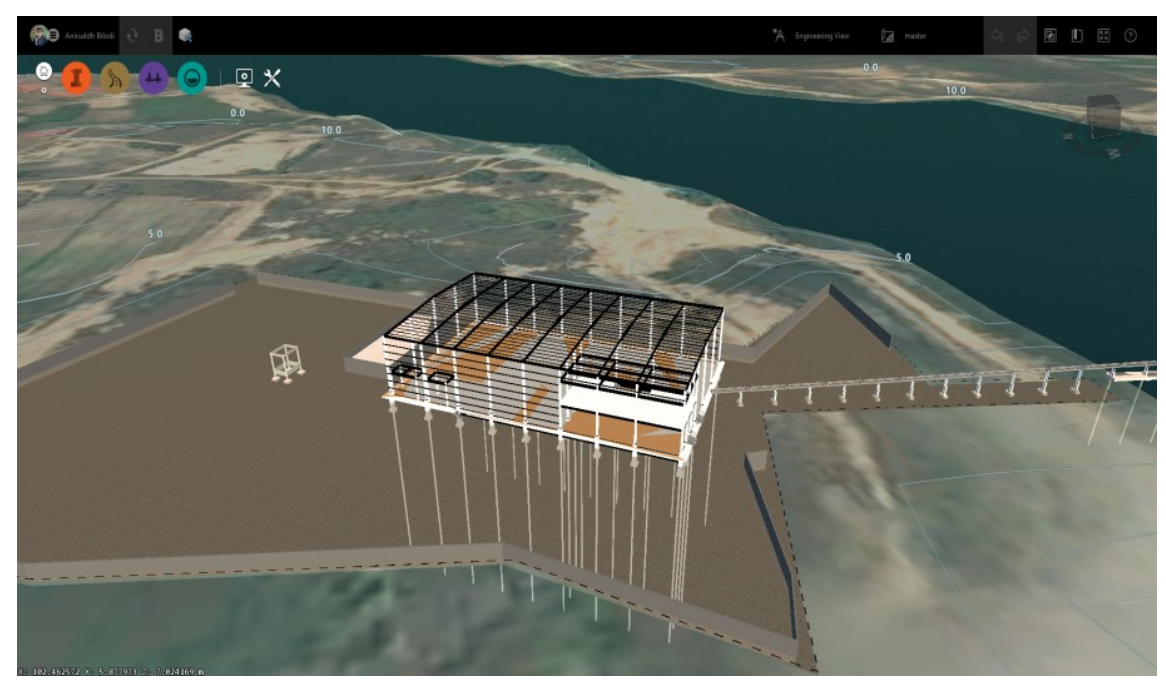

Figure 13. Side view of the site on actual topography

BIM 360 - This is one of the most revolutionary tools in BIM. BIM 360 is a cloud that offers one common uniform platform to Architects, engineers, contractors, clients and anyone who is related to the project. Construction players between each other can analyze, communicate, correct, and approve projects from one single platform without meeting each other. This increases the efficiency and productivity of the design and construction process. Once the tool is set to operate, BIM manager will send the invitation to required construction players. BIM manager will be the Admin of the project in BIM 360, as shown in the Figure 14. Only the Admin has the authority to give permission to construction players whether other construction players can join the project or not. Clash detection can also be done in BIM 360, as shown in the Figure 15. Construction players can also see the progress of the project by looking into models, drawings, analysis, and documents created in each discipline. Any correction required could be sorted instantaneously because construction players will always be connected to the cloud through BIM 360. 


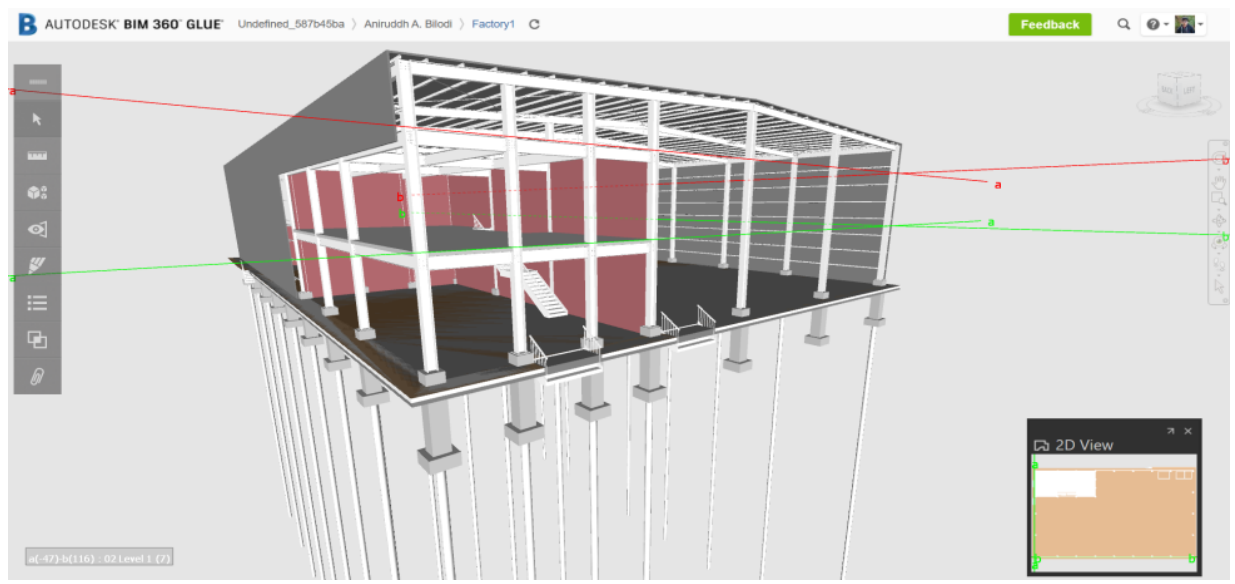

Figure 14. Admin managing the model in the cloud

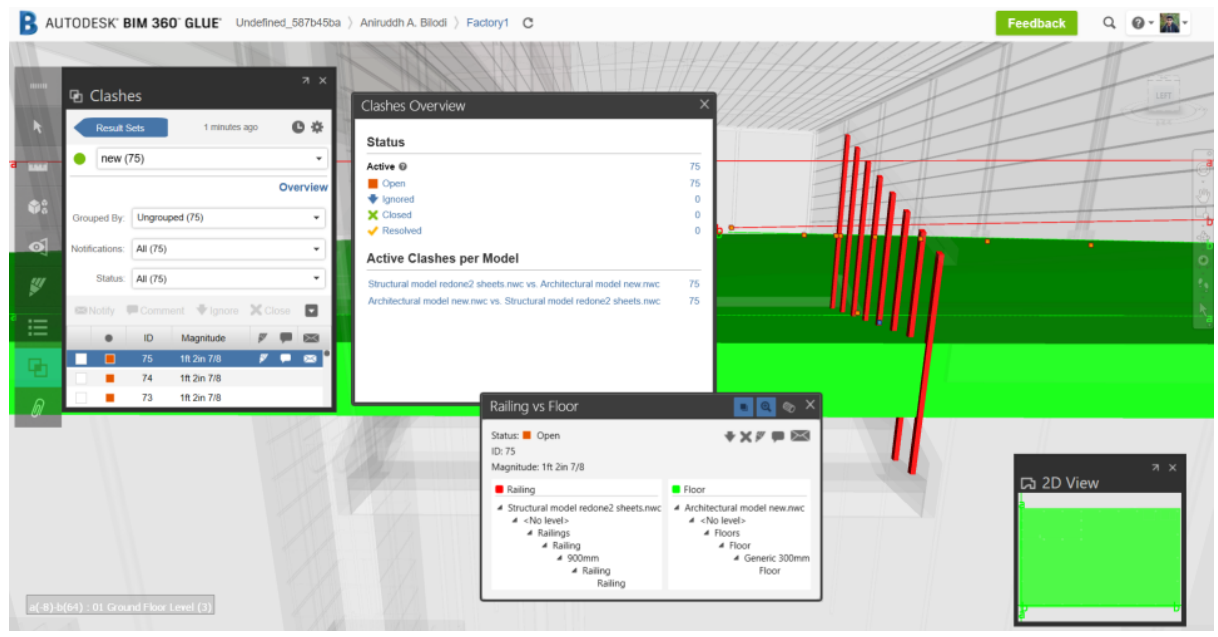

Figure 15. Clash detection in cloud

\section{Conclusion}

AEC industry is rapidly moving towards digitization where the industrial shift from $2 \mathrm{D}$ to $3 \mathrm{D}$ and from $3 \mathrm{D}$ to $\mathrm{BIM}$ is becoming mandatory in developed countries and developing countries. Each decade the process of construction is transforming and evolving, in which BIM has become a revolutionary way of planning, designing, executing, and documenting the construction process. But the implementation of BIM is the real challenge to the current AEC industry especially at the Small and Medium Enterprise level (SME's). AEC 
industry is lagging to implement BIM in their respective sector because of the absence of a Real-World BIM-based framework and the BIM sample in the current AEC industry.

Understanding of BIM and BIM implementation process is important for AEC professional. As this paper explains the concept of BIM, global standards for BIM utilization, BIM tools which are eminently used around the world and majorly this paper provides a framework for AEC professional to implement BIM. Framework navigates AEC professionals through each major process of BIM with respect to Structural discipline and BIM tool utilization. The framework would help to widen the usage of BIM eventually.

\section{Acknowledgement}

The author would like to extend his appreciation to MTC Floating Solutions Sdn. Bhd. for providing complete technical support and working space to complete this paper. And author would also like to appreciate Segi university for having Industrial associations where researchers can learn, work and grow at the industrial level.

\section{Reference}

(BSI), B. S. (2016). BIM level 2. Retrieved from https://bim-level2.org: https://bim-level2.org/en/about/

(CREAM), C. R. (2014). Issues and challenges in implementing BIM for SME's in The Construction Industry. Kuala Lumpur: Construction Research Institute of Malaysia (CREAM).

(ISO), T. I. (2018, December). Engineering BIM. Retrieved from https://www.engineering.com:

https://www.engineering.com/BIM/ArticleID/18351/ISO-Releases-FirstWorldwide-BIM-

(NBS), N. B. (2018). National BIM Report. National Building Specification.

Javad Majrouhi Sardroud, M. M. (2018). Barriers Analysis to Effective Implementation of BIM in the Construction Industry. 1. 
Pranav Bhagwat, R. S. (2016). Clash Detection - A New Tool in Project Management. 2016 IJSRSET, Volume 2, Issue 4 |, 193.

Weddikkara, H. S. (2013). Assessing the BIM maturity in a BIM infant industry. 63.

Zahrizan, N. M.-P. (2014). Exploring the Barriers and Driving Factors in Implementing Building Information Modelling (BIM) in the Malaysian Construction Industry: A Preliminary Study. The Institution of Engineers, Malaysia - Vol. 75, No. 1, 1. 